\title{
Effect of Fiber Diameter on the Spreading, Proliferation and Differentiation of Chondrocytes on Electrospun Chitosan Matrices
}

\author{
Sandra E. Noriega Gulnara I. Hasanova Min Jeong Schneider \\ Gustavo F. Larsen Anuradha Subramanian \\ Department of Chemical and Biomolecular Engineering, University of Nebraska - Lincoln, Lincoln, Nebr., USA
}

\section{Key Words}

Cytoskeleton - Differentiation - Tissue engineering of cartilage and bone

\begin{abstract}
Tissue-engineered neocartilage with appropriate biomechanical properties holds promise not only for graft applications but also as a model system for controlled studies of chondrogenesis. Our objective in the present research study is to better understand the impact of fiber diameter on the cellular activity of chondrocytes cultured on nanofibrous matrices. By using the electrospinning process, fibrous scaffolds with fiber diameters ranging from $300 \mathrm{~nm}$ to $1 \mu \mathrm{m}$ were prepared and the physicomechanical properties of the scaffolds were characterized. Bovine articular chondrocytes were then seeded and maintained on the scaffolds for 7 and 14 days in culture. An upregulation in the gene expression of collagen II was noted with decreasing fiber diameters. For cells that were cultured on scaffolds with a mean fiber diameter of $300 \mathrm{~nm}$, a 2-fold higher ratio of collagen II/collagen I was noted when compared to cells cultured on sponge-like scaffolds prepared by freeze drying and lyophilization. Integrin $\left(\alpha_{5}, \alpha V_{1} \beta_{1}\right)$ gene expression was also observed to be influenced by matrix morphology. Our combined results suggest that matrix geometry can regulate and promote the retention of the chondrocyte genotype.
\end{abstract}

Copyright $\odot 2011$ S. Karger AG, Basel

\section{Introduction}

Tissue engineering of articular cartilage involves the isolation of articular chondrocytes, or their precursor cells, followed by seeding onto a biocompatible matrix or scaffold, cultivation in a bioreactor, and further implantation into the defect or joint [Langer and Vacanti, 1993; Nerem, 2000]. In the development of cell-based therapies in cartilage tissue engineering, the material character of the scaffold, scaffold organization and ar-

\begin{tabular}{ll}
\hline Abbreviations used in this paper \\
\hline Collagen type I & C-I \\
Collagen type II & C-II \\
DMEM & Dulbecco's modified Eagle medium \\
ECM & extracellular matrix \\
F12 & nutrient mixture F12 \\
FDL & freeze drying and lyophilization \\
GAG & glycosaminoglycan \\
NF & nanofibrous \\
NFM & nanofibrous matrices \\
PBS & phosphate-buffered solution \\
PEO & polyethylene oxide \\
ROCK-1 & Rho-activated kinase 1 \\
SEM & scanning electron microscopy \\
TCP & tissue culture polystyrene plate \\
\hline
\end{tabular}

\section{KARGER}

(c) 2011 S. Karger AG, Basel

Fax +41613061234

E-Mail karger@karger.ch

www.karger.com 
chitecture are important because the scaffold serves as an initial template for cellular adhesion and have been reported to modulate cellular responses. Scaffolds based on both natural and synthetic polymers have been evaluated in both in vitro and in vivo cartilage tissue engineering applications [Minns et al., 1983; Dahlberg and Kreicbergs, 1991; Wakitani et al., 1994; Schuman et al., 1995; van Susante et al., 1995; Frondoza et al., 1996; Frenkel et al., 1997; Grande et al., 1997; Bryant and Anseth, 2002; Davis and Anseth, 2002; Hsu et al., 2002; Ma et al., 2002; Rocha et al., 2002]. While a variety of scaffold morphologies have been used in in vitro cartilage tissue engineering, a cell carrier substrate that mimics the naturally occurring environment in the articular cartilage matrix [Maroudas, 1979; Darling and Athanasiou, 2003a] is hypothesized to enable a favorable cellular response. Chondrocytes, the cell type that populates the articular cartilage, are embedded in a hierarchical matrix composed of type II collagen (C-II) fibrils that range from 100 to $300 \mathrm{~nm}$ [Maroudas, 1979; Darling and Athanasiou, 2003b]. Of all the fiber preparation methods available, the technique of electrospinning offers an attractive alternative to achieve these small fiber diameters [Matthews et al., 2002; Wnek et al., 2003; Yoshimoto et al., 2003] and has been used to prepare fibrous matrices with fiber diameters ranging from a few microns to $100 \mathrm{~nm}$ [Li et al., 2002, 2003; Matthews et al., 2003; Duan et al., 2004; Lee et al., 2004; Subramanian et al., 2004; Yang et al., 2004; Bhattarai et al., 2005; Kidoaki et al., 2005; Subramanian et al., 2005; Badami et al., 2006; Bhattarai et al., 2006].

Recent advances have enabled the fabrication of structures that better mimic the organization and hierarchy of the extracellular matrix (ECM), and subsequently, the effects of microtopography on cell adhesion, contact guidance, cytoskeletal organization, apoptosis, macrophage activation and gene expression have been evaluated [Clark et al., 1987; Britland et al., 1996; Chen et al., 1997; Thomas et al., 1999; McFarland et al., 2000; Dalby et al., 2004, 2005; Yang et al., 2004; Théry et al., 2006; Bashur et al., 2009]. For example, porous substrates were shown to possess increased accumulation of collagen and proteoglycans, compared to smooth surfaces, when chondrocytes were cultured on them [Spiteri et al., 2006; Théry et al., 2006]. Micropatterned substrates of varying sizes have also been reported to produce an interesting shift in cellular activity. A change from growth to apoptosis occurred when a significant dimension of the micropatterned surface changed from 40 to $5 \mu \mathrm{m}$ [Chen et al., 1997]. Differences in actin cytoskeleton were detected between immortalized human fibroblasts cultured on flat surfaces [Théry et al., 2006] and nanocolumns, in which defined stress fibers were formed on flat surfaces, and in contrast cortical actin was detected on nanocolumns [Dalby et al., 2004]. Recently, the effect of fiber diameter and alignment on cellular morphology, proliferation and gene expression of mesenchymal progenitor cells cultured on polyurethane-based nanofibrous (NF) scaffolds with varying fiber diameters and alignments were assessed. The expressions of ligament-specific markers were noted to be sensitive to decreasing fiber diameters, with maximum gene expression occurring in the matrices with the smallest fiber diameters. Additionally, increasing the fiber alignment was noted to influence the transcription factor associated with bone marrow stromal cells [Bashur et al., 2009].

The objective of this paper is to discuss the design and development of scaffolds that closely approximate the native ECMs of articular cartilage, which are primarily composed of collagen nanofibers, and to test the hypothesis that differences in matrix topography, namely fiber diameter, may alter and modulate chondrogenic gene expression and impact the organization of actin on fibrous matrices. The rationale that underlies our investigation is that the nanofibers will provide increased surface area for cellular interaction when compared to scaffolds made from freeze drying and lyophilization (FDL) of chitosan. The studies outlined in this paper permit the analysis of how biomimetic matrices impact biosynthesis and, thus, the regulation of chondrocyte function in biomimetic scaffolds under static culture conditions.

\section{Materials and Methods}

\section{Reagents}

All chemicals were of analytical grade or better. Chitosan with a degree of deacetylation of $83 \%$ was purchased from Vanson (Redmond, Wash., USA) and used without further purification. Polyethylene oxide (PEO) was purchased from Sigma-Aldrich, St. Louis, Mo., USA (MW 5,000,000).

\section{Isolation of Chondrocytes}

Discarded tissue from the shoulder joints of 6-month-old calves were obtained from a local abattoir, and chondrocytes were isolated using a protocol detailed elsewhere [Noriega et al., 2007]. Briefly, cartilage slices were cut, minced under aseptic conditions and incubated with pronase solution $(1 \mathrm{mg} / \mathrm{ml})$ in Dulbecco's modified Eagle medium/nutrient mixture F12 (DMEM/F12; Invitrogen, Calif., USA) for $1 \mathrm{~h}$ at $37^{\circ} \mathrm{C}$. Upon incubation, the slices were washed twice with a sterile phosphate-buffered solution (PBS; Gibco, Rockville, Md., USA) and incubated in a collagenase (Roche) solution $(1 \mathrm{mg} / \mathrm{ml}$ ) in a DMEM/F12 medium (Gibco, 
N.Y., USA) for $12 \mathrm{~h}$ at $37^{\circ} \mathrm{C}$ with slow agitation (50 rpm). The chondrocyte suspension was filtered through a $70-\mu \mathrm{m}$ sterile cell screen, centrifuged for $10 \mathrm{~min}$ at $200 \mathrm{~g}$. The pellet was washed with sterile PBS and resuspended in the DMEM/F12 medium supplemented with $10 \%$ FBS and containing a 100-mM HEPES buffer, $100 \mathrm{U} / \mathrm{ml}$ of penicillin, $100 \mu \mathrm{g} / \mathrm{ml}$ of streptomycin and $0.29 \mathrm{mg} /$ $\mathrm{ml}$ of L-glutamine. Then, the suspension was counted in a hemacytometer. The chondrocytes were expanded using DMEM/F12 with $10 \%$ FBS, $100 \mathrm{mM}$ HEPES buffer, $100 \mathrm{U} / \mathrm{ml}$ of penicillin, 100 $\mu \mathrm{g} / \mathrm{ml}$ of streptomycin and $0.29 \mathrm{mg} / \mathrm{ml}$ of $\mathrm{L}$-glutamine medium in passages 0 and 1 to allow cells to recover from the isolation step. In passage 2 and subsequent passages, cells were expanded using RPMI-1640 supplemented with $10 \%$ FBS and containing a 1-mM solution of sodium pyruvate, $100 \mathrm{mM}$ HEPES buffer, $100 \mathrm{U} / \mathrm{ml}$ of penicillin, $100 \mu \mathrm{g} / \mathrm{ml}$ of streptomycin, $0.29 \mathrm{mg} / \mathrm{ml}$ of L-glutamine and $10 \mu \mathrm{g} / \mathrm{ml}$ of ascorbic acid. Our choice to use RPMI-1640 as the cell culture medium was based on the following information: presence of hydroxyproline in the medium formulation and the positive documented effect of RPMI on C-II and glycosaminoglycan (GAG) production in chondrocytes seeded in 3D culture [Priddy et al., 2001]. The chondrocytes were expanded in a $75-\mathrm{cm}^{2}$ T flask at a cell density of $10^{4}$ cells $/ \mathrm{cm}^{2}$ in RPMI-1640 containing $10 \%$ FBS, $1 \mathrm{mM}$ solution of sodium pyruvate, $100 \mathrm{mM}$ HEPES buffer, $100 \mathrm{U} / \mathrm{ml}$ of penicillin, $100 \mu \mathrm{g} / \mathrm{ml}$ of streptomycin and 0.29 $\mathrm{mg} / \mathrm{ml}$ of L-glutamine. Bovine chondrocytes from passage 3 were used in all of the experiments.

\section{Preparation of the Chitosan Nanofiber Mat by}

\section{Electrohydrodynamic Methods}

To synthesize electrospun chitosan fibers of varying diameters, a previously published procedure was followed [Subramanian et al., 2004]. Briefly, chitosan of $83 \%$ deacetylation degree (Vanson Halo) was dissolved in a $1 \%$ acetic acid solution. Chitosan solutions yielding a conductivity of $366 \mu \mathrm{S} / \mathrm{cm}$, a surface tension of 30.34 dynes $/ \mathrm{cm}$, and a viscosity of $197.0 \mathrm{cP}$ at $98.5 \%$ torque were employed to produce the fibers. A small amount $(0.05 \%)$ of PEO (Sigma-Aldrich; MW 5,000,000) was added to a $1 \%(\mathrm{w} / \mathrm{v})$ solution of chitosan in acetic acid (Sigma-Aldrich), and the methods detailed in previous work were adopted to make the nanofibers. The electrospun scaffolds were first cut using a 5-mm diameter biopsy punch, followed by neutralization with an $\mathrm{NaOH}$ solution of $0.25 \mathrm{M}$ for $30 \mathrm{~min}$, then copiously rinsed with deionized water and sterilized with $70 \%$ ethanol for $1 \mathrm{~h}$.

\section{Preparation of FDL Scaffolds}

Chitosan scaffolds were also prepared by the FDL method by procedures detailed elsewhere [Subramanian et al., 2005]. Briefly, a 2 -ml solution of a $2 \%$ chitosan solution (in $1 \%$ acetic acid) was prepared and pipetted into each well of a 24-well tissue culture polystyrene plate (TCP; Falcon brand; Fisher, Pa., USA). The samples were then frozen at $-20^{\circ} \mathrm{C}$, and the frozen samples were lyophilized for $24-36 \mathrm{~h}$. The scaffolds were then neutralized with an $\mathrm{NaOH}$ of $0.25 \mathrm{M}$ solution for $30 \mathrm{~min}$, then copiously rinsed with deionized water and sterilized with a $70 \%$ ethanol solution for $1 \mathrm{~h}$. The scaffold samples used in the cell seeding experiments were $5 \mathrm{~mm}$ in diameter and $5 \mathrm{~mm}$ in thickness.

\section{Tensile Test}

The tensile properties of the electrospun fiber mats were measured by an Instron machine (Model 1123; Instron, Mass., USA).
Each sample was cut into rectangular specimens (length $3 \mathrm{~cm}$, width $1.0 \mathrm{~cm}$, gauge length $1.8 \mathrm{~cm}$ ). The tests were done at room temperature with the crosshead moving at $2 \mathrm{~mm} / \mathrm{min}$. The load cell used was $50 \mathrm{kgf}$. The load (in kgf) displacement (in $\mathrm{mm}$ ) data were recorded by the computer software (Bluehill; Instron, Ill., USA) provided by Instron and converted into stress-strain ( $\mathrm{mm} /$ $\mathrm{mm}$ ) curves to obtain ultimate tensile stress and Young's modulus.

\section{Cell Seeding}

Six sterilized specimens (5 $\mathrm{mm}$ in diameter) of each sample were placed on the bottom of the wells of a 6-well TCP (Falcon brand) and washed with sterile PBS and then wetted in RPMI medium (Gibco) for $24 \mathrm{~h}$ prior to cell seeding. Bovine chondrocytes were seeded onto the pre-wetted electrospun fibers at a seeding density of $3 \times 10^{4}$ cells/scaffold and were maintained for $3 \mathrm{~h}$ in an incubator at $37^{\circ} \mathrm{C}$ in a $5 \% \mathrm{CO}_{2}$ atmosphere, and subsequently $8 \mathrm{ml}$ of medium was added. The cells were cultured in RPMI medium (Gibco) plus 10\% FBS and $1 \times$ antibiotic-antimycotic solution (Gibco). The 6-well TCP was kept in a cell culture incubator at $37^{\circ} \mathrm{C}, 95 \%$ humidity and $5 \% \mathrm{CO}_{2}$, and the medium was changed every 2 days. The cells were cultured for 7 days before performing scanning electron microscopy (SEM) and were cultured for 5, 7 and 14 days for fluorescent staining.

Visualization of Cellular Morphology

For SEM, the cells were cross-linked with 2.5\% (v/v) glutaraldehyde (Sigma) in PBS, rinsed with PBS twice and gradually dehydrated with a series of ethanol solutions (20, 50, 75, 95 and $100 \%$ for $10 \mathrm{~min}$ each). Hexamethyldisilazane (Fisher) was used to remove $100 \%$ ethanol (15 min). The samples were dried overnight and sputter coated with Au-Pd before being examined under SEM (s3000N; Hitachi, Japan).

Visualization of the Actin Cytoskeleton

For fluorescent staining, cells were fixed in freshly made $4 \%$ (v/v) paraformaldehyde (Electron Microscopy Science, Pa., USA) in PBS for $2 \mathrm{~h}$ at room temperature. The cells were blocked and permeated with $0.25 \%$ (v/v) Triton X-100 (Sigma), $10 \mathrm{mg} / \mathrm{ml}$ of bovine serum albumin (fraction V; Sigma), $50 \mu \mathrm{l} / \mathrm{ml}$ of normal goat serum (Jackson Immunoresearch, Pa., USA) in PBS and incubated for $12 \mathrm{~h}$ at room temperature with Alexa 568 phalloidin (Invitrogen) at a dilution factor of $1: 100$ in $0.1 \%$ Triton, $1 \%(\mathrm{w} / \mathrm{v})$ bovine serum albumin, and $1 \%$ (v/v) normal goat serum in PBS. A confocal laser scanning microscope (Olympus FV500 Inverted, Olympus IX 81) was used to obtain the images.

\section{Cellular Viability by Live-Dead Assay}

A live-dead viability kit (Invitrogen) was used to determine cell viability. Cell-seeded scaffolds and fiber mats were rinsed with sterile PBS and incubated with a mixture of calcein-AM and ethidium homodimer-1 according to the manufacturer's instructions. The cells were visualized by inverted confocal microscopy.

\section{mRNA Gene Expression Analysis}

RNA was extracted from chondrocytes that were frozen under liquid nitrogen using $1 \mathrm{ml}$ of Trizol reagent (Invitrogen) to which $250 \mu \mathrm{g} / \mathrm{ml}$ of glycogen (Invitrogen) was added as a carrier. The integrity and purity of the isolated RNA was assessed by gel electrophoresis and A260/A280 absorbance ratios. RNA samples 
Table 1. Sequence of primers used in RT-PCR

\begin{tabular}{|c|c|c|c|c|}
\hline Genes & Accession No. & Primers (forward) & Primers (reverse) & $\begin{array}{l}\text { Size } \\
\text { bp }\end{array}$ \\
\hline C-I & XM591434 & 5'-CGTGATCTGCGACGAACTTA-3' & 5'-GCACGGAAATTCCTGTTGAT-3' & 315 \\
\hline C-II & AU743675 & 5'-CGGTAAGTGGGGCAAGACTA-3' & 5'-TCTGCCCAGTTCAGGTCTCT-3' & 315 \\
\hline Aggrecan & AU226866 & 5'-ATCCCAAAACGCCACTCTGG-3' & 5'-CTTGTGTCACCATCCACTCC-3' & 317 \\
\hline Integrin $\beta_{1}$ & OQ871214 & 5'-AGTCTGTGCTGAGCATAAAGAATG-3' & 5'-ATCATTAAAAGCTTCCAAATCAGC-3' & 354 \\
\hline Integrin $\alpha_{2}$ & XM613651 & 5'-CCAGTATTCCAACAGAAAGACACTT-3' & 5'-ACACTGTTCCCAGTAGAAATTGAAG-3' & 352 \\
\hline Integrin $\alpha_{5}$ & XM614854 & 5'-ACTTGCATCAACCTTAGCTTCTG-3' & 5'-GGCACACAGATATTGTCTTCTCC-3' & 398 \\
\hline Integrin $\alpha \mathrm{v}$ & BC151256 & 5'-TTGGAGCATCTGTGAGGTCAAAAC-3' & 5'-TTGAAATCTCCGACGGCCAC-3' & 415 \\
\hline Sox-9 & AF278703 & 5'-CTCAAGGGCTACGACTGGAC-3' & 5'-CGTTCTTCACCGACTTCCTC-3' & 205 \\
\hline Sox -5 & NM_001083471 & 5'-ACCTCACCTCAGAAGGCAGA-3' & 5'-ATCTGAGACGCAGCCAGTTT-3' & 371 \\
\hline mDial & XM_595101 & 5'-TTGCAAGAAAATGTGCAAGC-3' & 5'-AACGATGCTCAGCAGGAACT-3' & 331 \\
\hline RhoA & NM_176645 & 5'-AACAGGATTGGTGCTTTTGG-3' & 5'-AGTGCAGAGGAGGGCTGTTA-3' & 368 \\
\hline ROCK-1 & AY052529 & 5'-GCTCGAGAGAAGGCTGAAAATAG-3' & 5'-CATCTGCCCTTCATTCCCTCTG-3' & 342 \\
\hline GAPDH & XR_027343 & 5'-ACCCAGAAGACTGTGGATGG-3' & 5'-CCCAGCATCGAAGGTAGAAG-3' & 323 \\
\hline
\end{tabular}

(approximately $2 \mu \mathrm{g}$ ) were pretreated with 3 units of DNase I for $20 \mathrm{~min}$ at room temperature using the DNA-free kit (Invitrogen), after which the enzyme was inactivated at $65^{\circ} \mathrm{C}$ in the presence of $2 \mathrm{mM}$ EDTA. The DNase-free RNA preparations were subsequently used with $50 \mathrm{ng}$ of random hexamer primers and SuperScript II Reverse Transcriptase-based kit (Invitrogen, Life Technologies) to synthesize the first strand of $\mathrm{cDNA}$ at $42^{\circ} \mathrm{C}$ for 50 min. One microliter (for GAPDH) or $3 \mu$ l (for the rest of the genes) of the cDNA template were expanded using the Taq DNA polymerase (Invitrogen) using the following PCR reaction conditions: a $94^{\circ} \mathrm{C}$ denaturation for $45 \mathrm{~s}$, a $55^{\circ} \mathrm{C}$ annealing period of $30 \mathrm{~s}$, a $72^{\circ} \mathrm{C}$ extension period of $1 \mathrm{~min}$ and a final extension at $72^{\circ} \mathrm{C}$ for $10 \mathrm{~min}$ using the forward and reverse gene-specific primers specified in table 1. GAPDH was amplified for 31 cycles, and the rest of the genes were amplified for 35 cycles. GAPDH, a housekeeping gene, was used as a loading control of cDNA samples on agarose gel, and the PCR products were loaded on a $1 \%$ agarose gel, containing ethidium bromide, and photographed with UV light excitation. Gene ascension numbers are detailed in table 1 .

\section{Western Blot Analysis}

The chondrocyte cells $\left(1.3 \times 10^{6}\right.$ to $\left.3.6 \times 10^{6}\right)$, recovered from 36 scaffolds after 14 days in culture, were incubated in a lysis buffer (40 mM Tris-HCI, pH 8.0, 120 mM NaCI, 0.5\% Nonidet P-40, $100 \mu \mathrm{g} / \mathrm{ml}$ of phenylmethylsulfonyl fluorid and a protease inhibitor; Roche Applied Science) at the recommended concentration for $20 \mathrm{~min}$ at $4^{\circ} \mathrm{C}$. After centrifugation at $15,000 \mathrm{~g}$ for $20 \mathrm{~min}$, the protein concentration in the supernatant was measured by the bicinchoninic acid (Thermo Scientific Pierce, Ill., USA) method, and a volume equivalent to a total protein $(8 \mu \mathrm{g} /$ well $)$ was subjected to SDS-PAGE analysis on a 4-12\% NuPAGE gel. SDS-PAGE was performed using the NuPAGE system (Invitrogen), followed by Western blotting to polyvinylidene fluoride using the NuPAGE system (Invitrogen), according to the manufacturer's instructions. After the transfer, the membranes were blocked with $0.5 \%$ casein in Tris-buffered saline. Upon completion of the blocking step, the membranes were incubated with primary antibodies (1:1,000 dilution) against type I collagen (C-I), C-II and aggrecan for $2 \mathrm{~h}$ in separate experiments. Actin $(\gamma)$ protein was used as the loading control. The primary antibodies used in the Western blots were mouse anti-human C-II, rabbit anti-bovine C-I, mouse antihuman aggrecan and mouse anti-actin. All primary antibodies were purchased from Millipore (Bedford, Mass., USA), and all antibodies used in our study cross-reacted with respective bovine proteins. Protein bands were visualized using the ECL plus detection system (Amersham Pharmacia Biotech).

\section{Quantification Analysis}

Band intensities were quantified by densitometry using ImageQuant software (version 5.2, Molecular Dynamics). The values reported were normalized to control. For the analysis of mRNA levels, data represent the mean and standard deviation (SD) values of 3 independent estimations.

\section{Statistical Analysis}

Student's t test was used for statistical analysis, and statistical differences were declared as $\mathrm{p}<0.05$ or $\mathrm{p}<0.01$ or $\mathrm{p}<0.02$. 


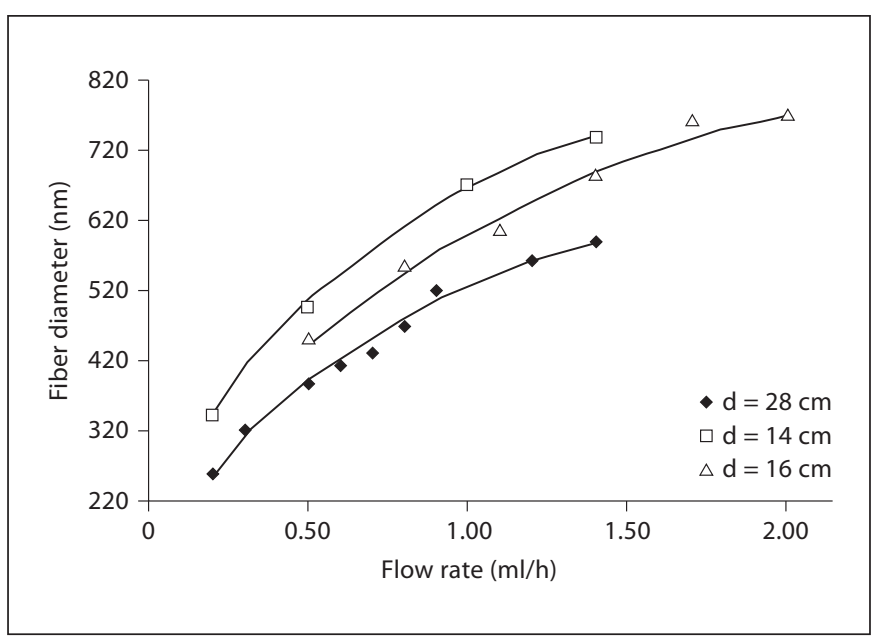

Fig. 1. Relationship between flow rate and fiber diameter. Chitosan solution ( $1 \% \mathrm{w} / \mathrm{v}$ in acetic acid, conductivity $366 \mu \mathrm{S} / \mathrm{cm}$, a surface tension of 30.34 dynes $/ \mathrm{cm}$, and a viscosity of $197.0 \mathrm{cP}$ at $98.5 \%$ torque) containing a small amount $(0.05 \%)$ of PEO (MW $5,000,000)$ was electrospun at a constant voltage of $8.0 \mathrm{kV}$. The obtained fibers were collected and analyzed by SEM analysis. Mean fiber diameters are reported. $\mathrm{d}=$ Tip to collector distance.

\section{Results}

By using a strategy that lowers the surface tension of the solution, fibers were prepared from a $1 \%(\mathrm{w} / \mathrm{v})$ solution of chitosan in acetic acid using a modified electrospinning process developed in our laboratory, the details of which are reported elsewhere [Subramanian et al., 2005]. In the present study, a model-driven approach [Fridrikh et al., 2003] was adopted to prepare fibers with diameters ranging from $300 \mathrm{~nm}$ to $1 \mu \mathrm{m}$, in which the surface tension and other properties of the solutions were measured, volumetric flow rates were controlled with the aid of digitally controlled syringe pumps and the electric current was measured. The model predicts a terminal jet diameter as a product of balance between normal stresses due to surface tension and surface charge repulsion. The resulting equation is the following:

$$
h_{t}=\left(\gamma \cdot \bar{\varepsilon} \cdot \frac{Q^{2}}{I^{2}} \cdot \frac{2}{\pi(2 \ln \chi-3)}\right)^{1 / 3}
$$

where $h_{t}=$ terminal jet radius $(\mathrm{m}), \gamma=$ surface tension $(\mathrm{N} / \mathrm{m}), \bar{\varepsilon}=$ dielectric constant of air, $\mathrm{Q}=$ flow rate $\left(\mathrm{m}^{3} / \mathrm{s}\right)$, $\mathrm{I}=$ electric current $(\mathrm{A})$, and $\chi \approx R / h$ is the dimensionless wavelength of the instability. First, a solution with a known composition was electrospun, and the resultant fiber diameters were determined by SEM. For a given formulation, a quantitative dependence of the mean fiber diameter (in $\mathrm{nm}$ ) on volumetric flow rate for different voltages was obtained (fig. 1). Fibers with diameters of 300,500 and $1,030 \mathrm{~nm}$ were prepared by the judicious manipulation of the independent variables and the physical properties of the solution.

Fibrous mats with 3 different ranges of fiber diameters were prepared and are denoted in this paper as follows: sample A, $1,030 \pm 260 \mathrm{~nm}$; sample B, $545 \pm 173 \mathrm{~nm}$; sample C, $323 \pm 95 \mathrm{~nm}$ in the dry state. As observed from the SEM (fig. 2), the fiber orientation in the mats is random, and the fiber diameters are considerably uniform. The thickness of the fiber mats was determined in both the dry and the hydrated stage. In the dry state, by SEM, a thickness of $100 \mu \mathrm{m}$ for sample A, $70 \mu \mathrm{m}$ for sample B and $50 \mu \mathrm{m}$ for sample $\mathrm{C}$ was obtained. It was difficult to obtain mats with similar thickness due to the shield effect upon electrospinning. After $20 \mathrm{~h}$ of electrospinning, a random deposition of fibers around the collector was noted, and a considerable amount of material did not contribute to the mat formation. When hydrated, the thickness was found to increase, possibly due to the hydrogel nature of the chitosan fibers, and the following thickness was obtained: $200 \mu \mathrm{m}$ for samples A and B and $100 \mu \mathrm{m}$ for sample $\mathrm{C}$. The fiber diameter was also altered in the wet state: sample A, 1,333 $\pm 200 \mathrm{~nm}$; sample B, $698 \pm$ $185 \mathrm{~nm}$; sample C, $435 \pm 95 \mathrm{~nm}$. A tensile modulus of $2.10 \pm 0.40,1.92 \pm 0.98$ and $2.97 \pm 0.95 \mathrm{MPa}$ was recorded for samples A, B and C, respectively. No significant difference in the tensile modulus was observed between samples.

SEM was used to observe the morphology, cell adhesion, spreading and the interaction of cells with the NF mats. Figure 3 shows SEM images of chondrocytes cultured on the chitosan nanofibers and scaffolds prepared by FDL after 7 days in culture. On FDL scaffolds (fig. 3a), cells were observed to proliferate and possess a rounded morphology, which is indicative of the chondrocytic phenotype [Benya and Shaffer, 1982]. The fiber diameter was observed to impact the overall morphology of the seeded chondrocytes. For example, figure $3 \mathrm{~b}$ shows chondrocyte cells that were seeded on NF scaffolds with a mean fiber diameter of $1 \mu \mathrm{m}$. As noted in figure 3b, the cells appeared to be flattened and were attached to the surfaces by discrete filopodia and exhibited long and numerous microvilli on their surfaces. Figure $3 c$, d shows the SEM images of chondrocyte cells seeded on NF scaffolds with a mean fiber diameter of 500 and $300 \mathrm{~nm}$, respectively, after 7 days in culture. 

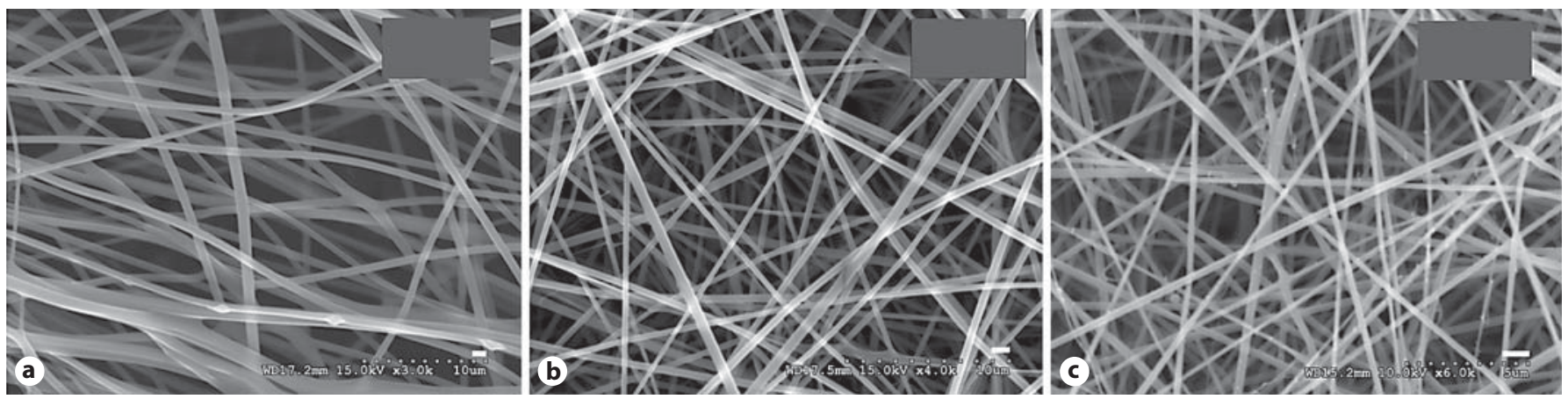

Fig. 2. SEM images of fibrous scaffolds in the dry state. a Sample A: 1,030 $\pm 260 \mathrm{~nm}$. b Sample B: $545 \pm 173 \mathrm{~nm}$. c Sample C: $323 \pm$ $95 \mathrm{~nm}$. Scale bar $=1 \mu \mathrm{m}$.

Fig. 3. Morphology of chondrocytes seeded on scaffolds. SEM images of chondrocytes cultured on FDL scaffolds (a), NFM with a mean diameter of $1 \mu \mathrm{m}$ (b), NFM with a mean diameter of $500 \mathrm{~nm}$ (c), and NFM with a mean diameter of $300 \mathrm{~nm}$ (d). Scale bars $=50 \mu \mathrm{m}(\mathbf{a}, \mathbf{b}, \mathbf{d})$ and $20 \mu \mathrm{m}(\mathbf{c})$.
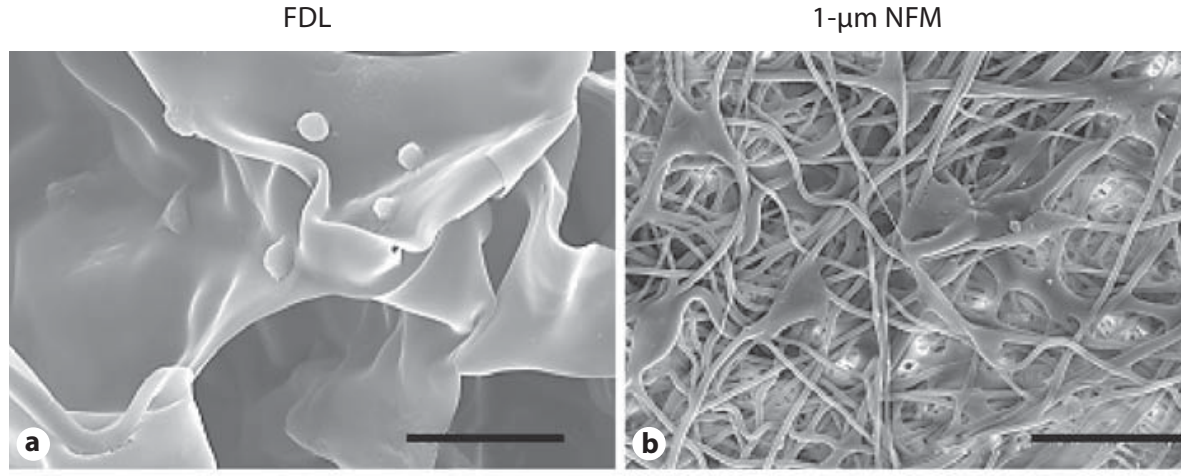

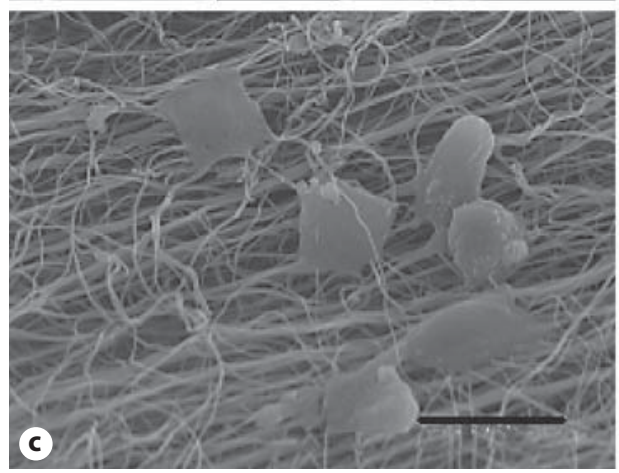

500-nm NFM

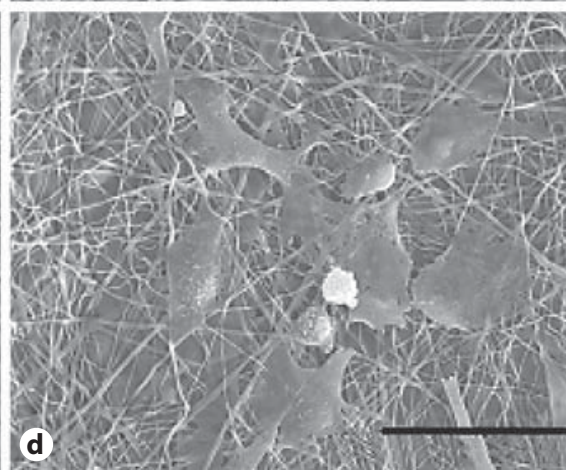

300-nm NFM
The live-dead assay (fig. 4) was used to assess the viability of chondrocyte cells seeded on FDL and NF scaffolds. Live cells, stained green, appeared to adhere well and exhibited a normal morphology on all the surfaces examined. Using a cell counter macro available on Image $^{\mathrm{TM}}$, the total number of green (live) cells were counted (fig. 4). Live cells on the NF scaffolds with a fiber diameter of $300 \mathrm{~nm}$ were significantly higher when compared to the FDL scaffold and exhibited a distribution of higher uniformity.
The cytoskeletal matrix of seeded chondrocytes was visualized by immunostaining. Figure 5 shows the actin cytoskeleton of the chondrocytes seeded and maintained on FDL scaffolds and electrospun fiber mats at different days in culture. A mixed distribution with the majority of cells presenting non-filamentous actin with cortical distribution was noted in figure $5 \mathrm{a}$, which shows the actin cytoskeleton of representative cells that were cultured on FDL scaffolds. At the end of 5 days in culture, no visible difference was noted in the organization of cytoskeletal 

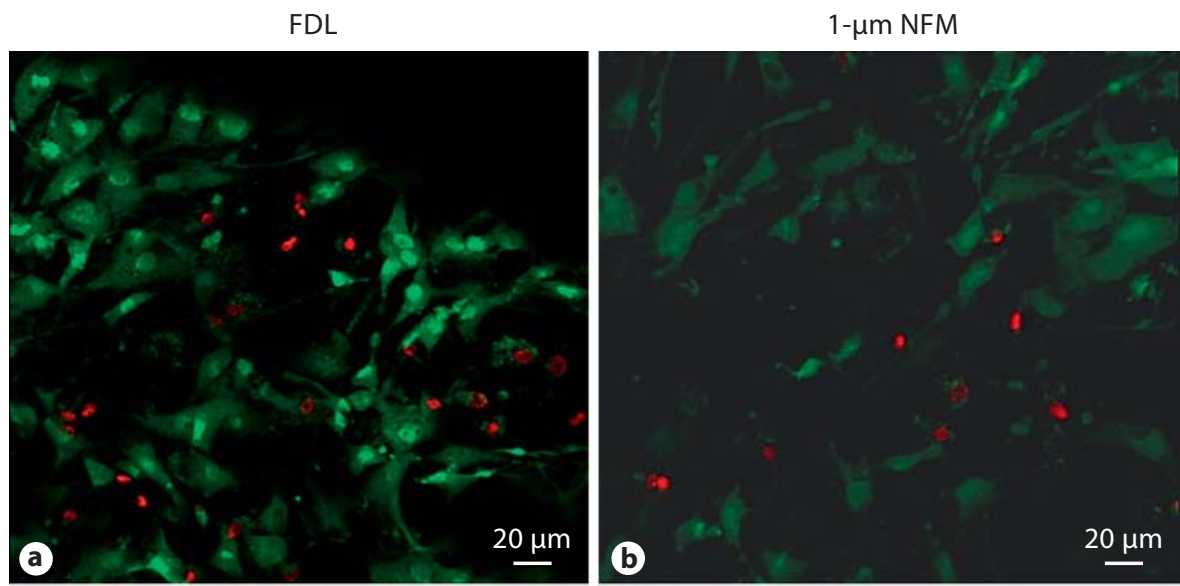

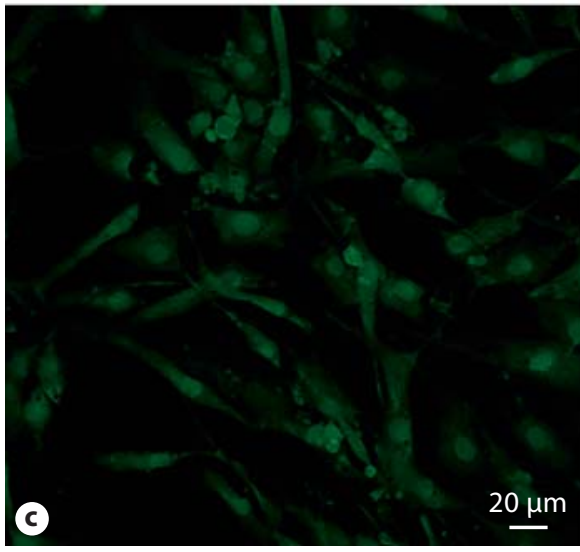

500-nm NFM

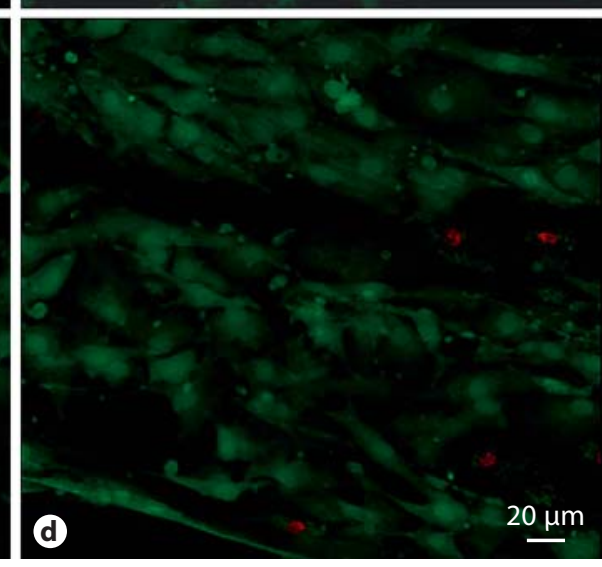

300-nm NFM

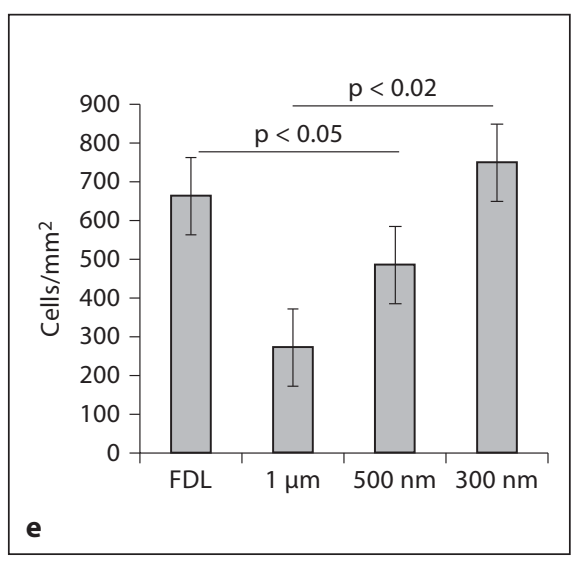

digitally processed using the NIH Image ${ }^{\mathrm{TM}}$ program; the cell counter macro was used to count number of live cells (green) and dead cells (red). Cell densities were calculated and more than 3 panels were processed and evaluated for each condition (e). actin among the NF scaffolds (fig. 5b-d). Figure 5b shows the actin cytoskeleton of representative cells that were cultured on NF scaffolds with a mean diameter of $1 \mu \mathrm{m}$. No special organization of actin was noted, and no meshlike structures or filamentous actin were observed. Only a very faint cortical distribution was detected. Figure $5 c$, $\mathrm{d}$ shows the actin cytoskeleton of representative cells that were cultured on NF scaffolds with a mean diameter of 500 and $300 \mathrm{~nm}$, respectively. Similar to figure 5b, a cortical distribution of actin was noted, while the cells cultured on NF scaffolds with a mean diameter of 500 and $300 \mathrm{~nm}$ presented a starting state of actin organization in the shape of short filaments, as seen in figure $5 c$, $d$ (white arrows). Non-filamentous actin distribution with very few stress fibers (fig. 5e) was noted for cells cultured for 7 days on FDL scaffolds. A non-filamentous distribution of actin was observed for cells cultured for 7 days on NF scaffolds with a mean fiber diameter of $1 \mu \mathrm{m}$ (fig. 5f), while cells cultured on NF scaffolds with a mean fiber diameter of $500 \mathrm{~nm}$ were noted to develop some stress fibers (fig. 5g). Interestingly, the actin distribution of cells that were cultured on NF scaffolds with a mean diameter of $300 \mathrm{~nm}$ were noted to resemble the actin distribution in uncultured cartilage [Durrant et al., 1999] and of chondrocytes encapsulated in alginate [Idowu et al., 2000] (fig. 5h). At the end of 14 days in culture, similar cellular morphologies were noted for cells cultured on FDL and NF scaffolds with a mean fiber diameter of $1 \mu \mathrm{m}$ (fig. $5 \mathrm{i}$, j). Figure 51 shows the change in overall morphology for cells seeded and cultured on the 300-nm fiber diameter 


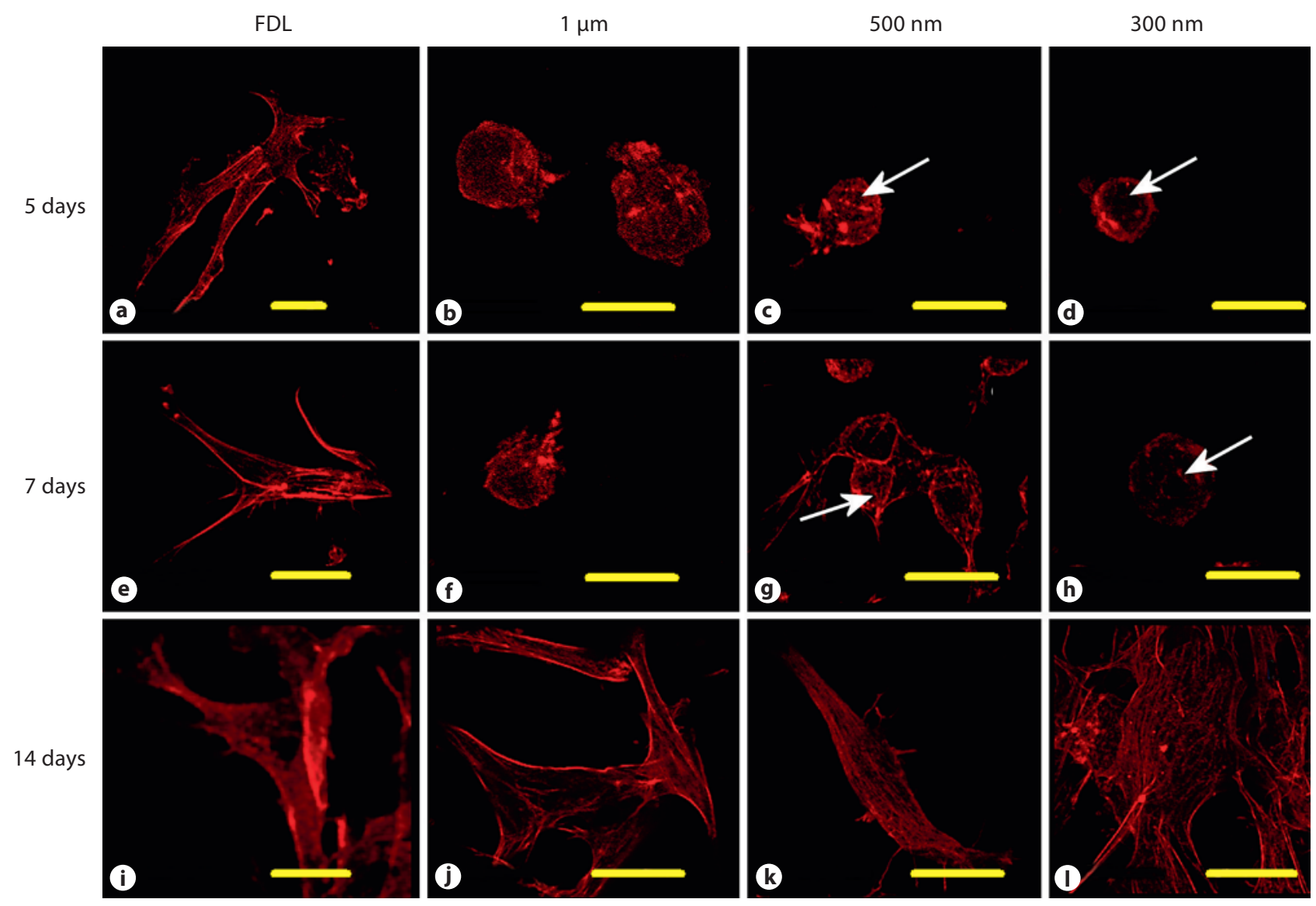

Fig. 5. Visualization of the actin cytoskeleton. Cell-seeded scaffolds were fixed in $4 \%$ paraformaldehyde in PBS, penetrated with $0.1 \%$ Triton X-100 in PBS and incubated with Alexa 568 phalloidin. Confocal images were obtained on Olympus FV500 Inverted (Olympus IX 81). Scale bar $=10 \mu \mathrm{m}$. Arrows indicate actin organization in the shape of short filaments.

at the end of 14 days in culture. The effect of nanofiber diameter on cell response is appreciated in the very distinct features shown by actin organization on the NF scaffolds with varying fiber diameter.

The ability of the NF scaffolds to promote chondrogenic redifferentiation was assessed by RT-PCR for cartilage-specific gene markers, and the expression was normalized to GAPDH as shown in figure 6. The NF scaffolds were able to sustain differentiation on the basis of the mRNA expression levels of C-II and aggrecans (GAG). The ratio of C-II/C-I, which is used as a differentiation marker, was observed to be impacted by fiber diameter (fig. 6a-c).

Integrin subunits, $\alpha_{2}, \alpha_{5}, \alpha \mathrm{v}$ and $\beta_{1}$, have been postulated to be involved in mechanochemical transduction pathways and are shown to be modulated by nanotopographical features [Chen et al., 1997; Loeser, 2000; Cu- kierman et al., 2001; Wong and Carter, 2003; Powell et al., 2006; Torres et al., 2008; Wood et al., 2008]. Thus, in this study, the effect of the fiber diameter of the NF matrices (NFM) on the gene expression of selected integrins was studied. Figure $6 \mathrm{~d}$ shows the gene expression of integrins $\left(\alpha_{2}, \alpha_{5}, \alpha \mathrm{V}, \beta_{1}\right)$ assessed by RT-PCR and normalized to GAPDH. The cells grown on the TCP are included as a control in this study. Compared to NF scaffolds, the gene expression of selected integrins was noted to be higher on FDL scaffolds.

The expressions of chondrocytic markers, namely C-II, C-I and GAG, were also assayed by Western blot analysis of the cell lysates using specific antibodies (fig. 7). The ratio of C-II/C-I is often considered to be a better marker for differentiating the healthy chondrocyte versus the fibrocartilaginous phenotype [Park et al., 2007]. The ratio of C-II/C-I was noted to be the highest in cell 

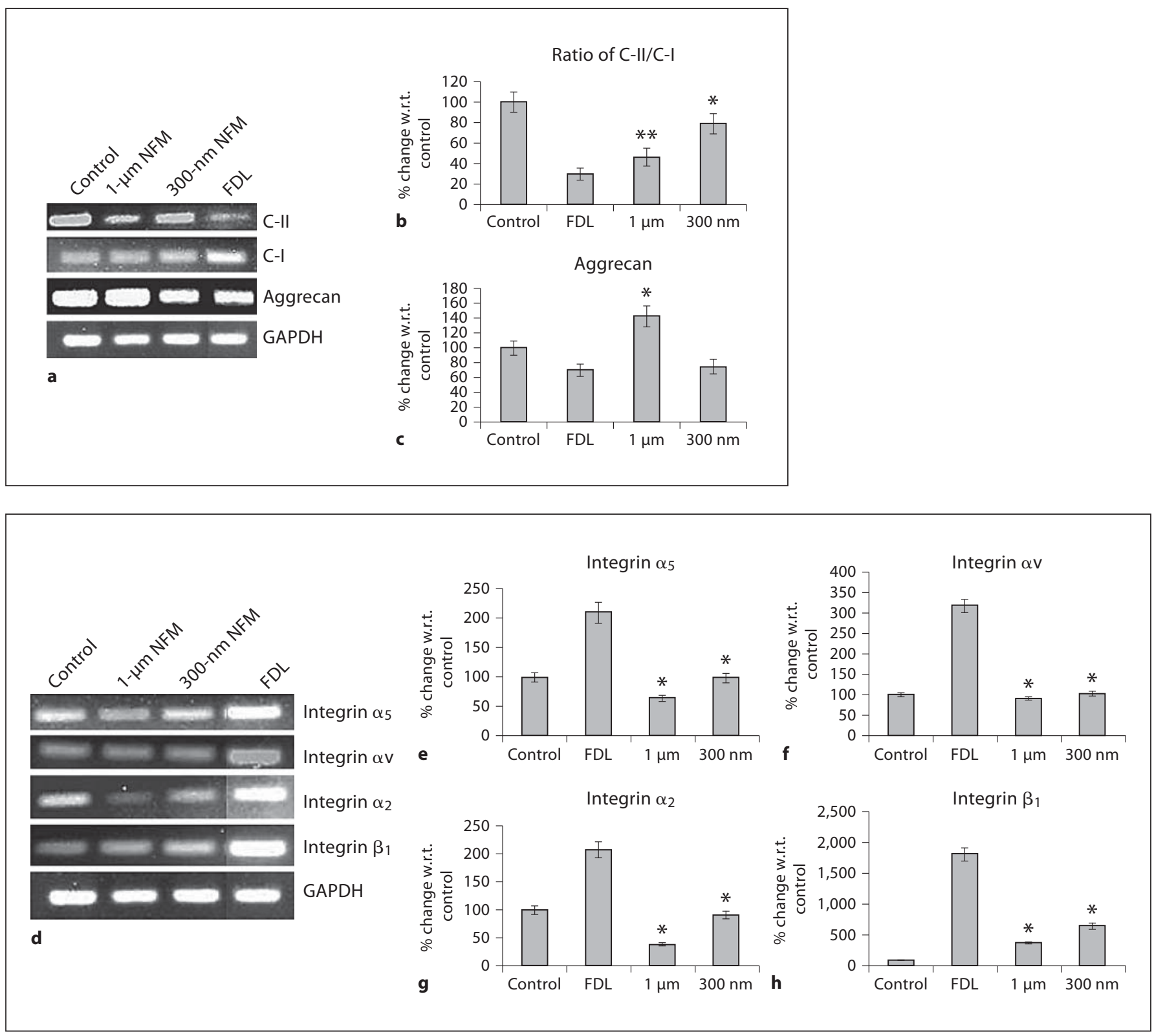

Fig. 6. a Analysis of the molecular responses of chondrocytes cultured on chitosan scaffolds (FDL and NFM). The mRNA levels of C-II, C-I and aggrecan genes were measured by RT-PCR using the specific primers listed in table 1 . The GAPDH gene was used as a loading control. Cells from freshly isolated chondrocytes served as controls. b, c Data were normalized to the controls and are reported as a the mean of 3 independent estimations with error bars, where the error bar represents $1 \mathrm{SD}$, and significant differences with respect to FDL are indicated $\left({ }^{*} p<0.05 ;{ }^{* *} p<0.01\right)$. The band intensities were determined using a commercial densitometric software and reported. d Analysis of the molecular re- sponses of chondrocytes cultured on chitosan scaffolds (FDL and NFM). The mRNA levels of $\alpha_{5}, \alpha \mathrm{v}, \alpha_{2}$ and $\beta_{1}$ genes were measured by RT-PCR using the specific primers listed in table 1 . The GAPDH gene was used as a loading control. Cells from freshly plated chondrocytes served as controls. e-h Data were normalized to the controls and are reported as a the mean of 3 independent estimations with error bars, where the error bar represents 1 $\mathrm{SD}$, and significant differences with respect to FDL are indicated $\left({ }^{*} \mathrm{p}<0.05\right)$. The band intensities were determined by using a commercial densitometric software and reported. 
Fig. 7. Western blot analyses of the cell lysates. Chondrocytes cultured on FDL and NFM were released, lysed and assayed for C-I, C-II and aggrecan by Western blot analyses. Actin protein was used as a loading control. Cells from freshly plated chondrocytes served as controls. The band intensities were determined using commercial densitometric software and reported. Significant differences with respect to FDL are indicated $\left({ }^{*} \mathrm{p}<0.05\right.$; $\left.{ }^{* * *} \mathrm{p}<0.02\right)$. The ratio of C-II/C-I is plotted.

Fig. 8. Analysis of the molecular responses of chondrocytes cultured on chitosan scaffolds (FDL and NFM). The mRNA levels of indicated genes were measured by RT-PCR using the specific primers listed in table 1. The GAPDH gene was used as a loading control. The band intensities were determined using commercial densitometric software and reported. Data were normalized to the controls and are reported as a the mean of 3 independent estimations with error bars, where the error bar represents $1 \mathrm{SD}$, and significant differences with respect to FDL are indicated $\left({ }^{* * *} \mathrm{p}<0.02\right)$. The ratio of Sox-5/Sox- 9 was calculated and plotted.
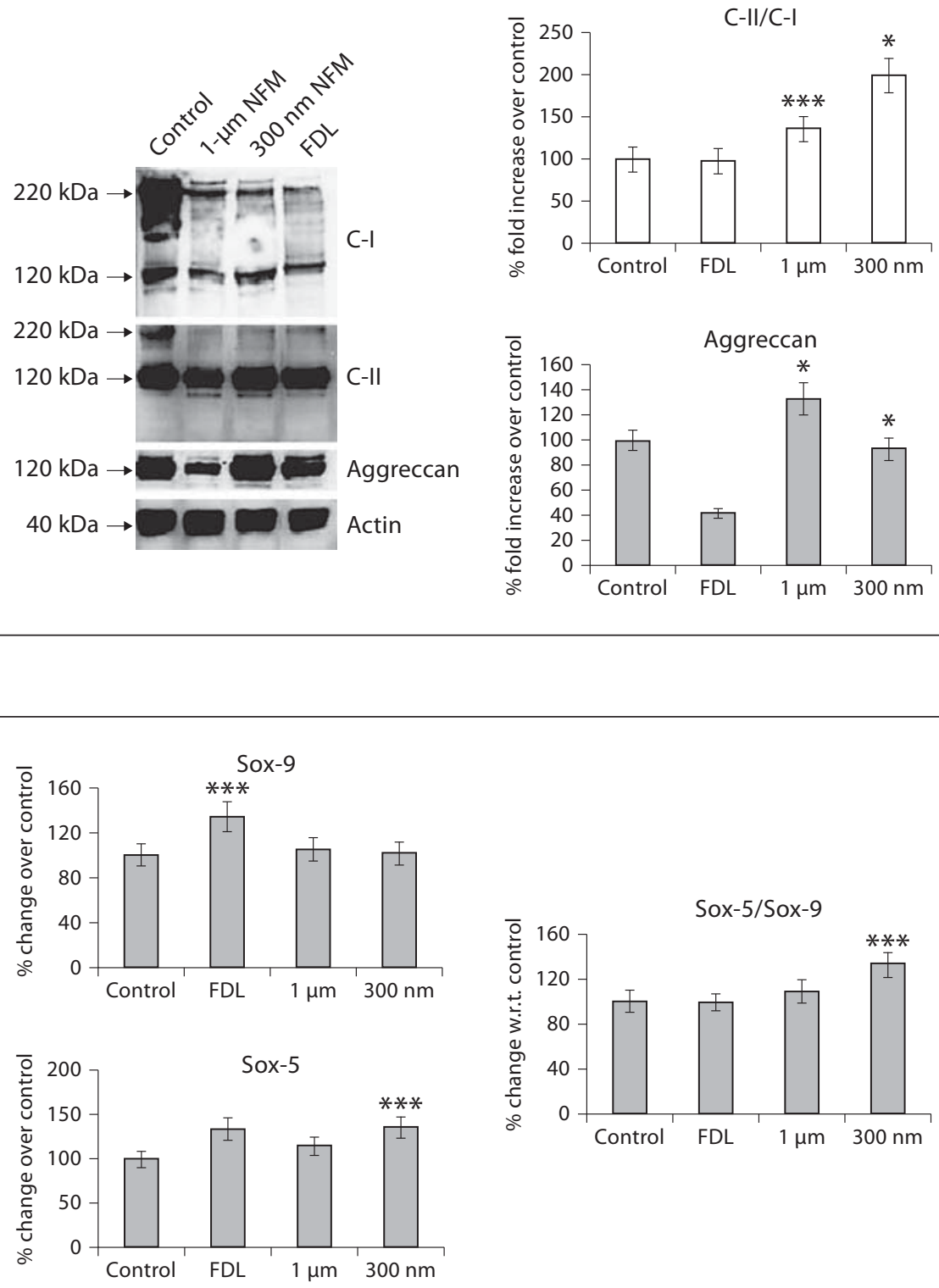

lysates from 300-nm scaffolds and was significantly different from the control and FDL scaffolds. When estimating C-I, band intensities at 120 and $240 \mathrm{kDa}$ were taken into calculation. Interestingly, the amount of aggrecan in the cell lysates from different NFM did not show any appreciable change compared to the control; however, lower amounts of aggrecan were noted in samples obtained from FDL scaffolds.

The only transcription factor required for chondrogenesis is Sox-9, as it directly regulates the transcription of C-II and the aggrecan gene in conjunction with the related Sox-5 and Sox- 6 genes [Lefebvre and De Crombrugghe, 1998; Bi et al., 1999; Woods and Beier, 2006]. Thus, the gene expression of Sox- 9 and Sox- 5 was also assessed and is shown in figure 8 . While a modest enhancement in the gene expression of Sox-5/Sox- 9 was noted on NF scaffolds with a mean diameter of $300 \mathrm{~nm}$, in general, similar pixel areas were noted for all matrices.

As reported previously, Rho-activated kinase 1 (ROCK-1) [Parker et al., 2002], which has been identified 


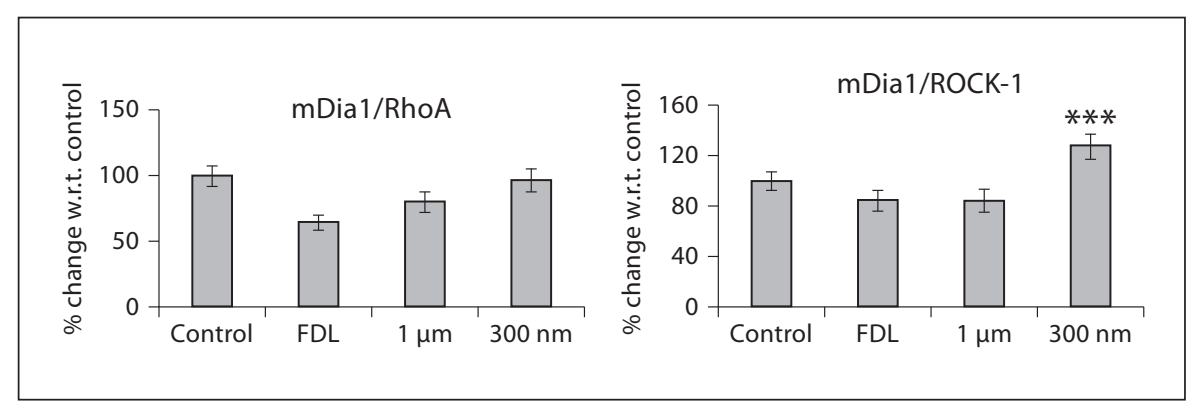

Fig. 9. Analysis of the molecular responses of chondrocytes cultured on chitosan scaffolds (FDL and NFM). The mRNA levels of indicated genes were measured by RT-PCR using the specific primers listed in table 1 . The GAPDH gene was used as a loading control. The band intensities were determined using commercial densitometric software and reported. Data were normalized to the controls and are reported as a the mean of 3 independent estimations with error bars, where an error bar represents $1 \mathrm{SD}$, and significant differences with respect to FDL are indicated $\left({ }^{* * *} \mathrm{p}<\right.$ 0.02). The ratios of $\mathrm{mDia} 1 / \mathrm{ROCK}-1$ and $\mathrm{mDia} / \mathrm{RhoA}$ were calculated from the band intensities obtained. as a key element in the formation of stress fibers, and mDial, which promotes actin polymerization and regulates the alignment of stress fibers with microtubules, act jointly in controlling the cytoskeletal rearrangements and stabilize the normal cell shape in the scaffold [Ishizaki et al., 2001; Mammoto et al., 2004]. Hence, in this study, the gene expression of both ROCK-1 and mDial was analyzed to ascertain their roles in the differences in cellular morphology noted in NFM. Figure 9 shows the gene expression of ROCK-1, RhoA and mDial from cells extracted from FDL and NF scaffolds. The gene expressions of ROCK-1, RhoA and mDial were not significantly impacted by the nature of the substrate.

\section{Discussion}

The electrospinning variables, namely tip-collector distance, applied voltage and volumetric flow rate, were shown to affect the fiber diameter. At an initial chitosan concentration of $1 \%(\mathrm{w} / \mathrm{v})$, and for tip to collector distances of 14 and $16 \mathrm{~cm}$, respectively, the fibers solidified before reaching the terminal jet diameter. Increasing the tip to collector distance to $28 \mathrm{~cm}$ allowed the fibers to reach the terminal jet diameter. This is evidenced by the position of the corresponding solid lines in figure 10 lying above $(14$ and $16 \mathrm{~cm})$ and below $(28 \mathrm{~cm})$ the theoretically predicted line (dashed line, fig. 10). Although the experimental data correlate well in light of the model proposed by Fridrikh et al. [2003], it was anticipated that the jet diameter would decrease due to solvent evaporation followed by fiber formation; however, the physical prop- erties of the electrospun solution must remain constant in the model. The changes in the concentration of the solution exiting the jet as a result of solvent evaporation cause changes in surface tension, which, in turn, is likely to affect the predicted jet diameter. These phenomena are not accounted for in the model.

Electrospinning has been extensively used to generate scaffolds with nanoscale topography. However, the mechanisms by which cells adapt and respond to nanoscale topography remain unclear and are worthy of investigation. It has been hypothesized that integrin $\alpha_{5} \beta_{1}$, a chondrocyte fibronectin receptor, regulates the interactions between ECMs and chondrocytes [Enomoto-Iwamoto et al., 1997] and also participates in signal mechanotransduction [Enomoto-Iwamoto et al., 1997; Lee et al., 2000; Lucchinetti et al., 2004; Millward-Sadler and Salter, 2004]. It is also widely known that chondrocytes alter their phenotype during cell culture, developing a fibroblastic-like appearance that is also accompanied by a change in gene expression [Schmal et al., 2006] when cultured on TCPs. However, this observation does not always hold true as demonstrated in older reports [von der Mark et al., 1977; Benya and Shaffer, 1982]. As shown in figure 3 , the cellular shape of chondrocytes was noted to change according to the matrix topography. Even though a non-rounded shape was detected for cells in sample C, C-II expression was not lost, compared to the control (fig. 8). We speculate that the cells are responsive to their environment, dedifferentiating when they are extracted from natural ECM and plated on flat surfaces and reforming the chondrocytic shape when cultured in 3D matrices [Kino-Oka et al., 2005; Terada et al., 2005; 
Fig. 10. Model analysis: log of fiber diameter versus $\log$ of $\mathrm{Q} / \mathrm{I}$ for different flow rates. The dashed line represents the terminal jet diameter $\left(D_{t}\right)$ predicted by theory. The solid lines represent experimentally obtained points. Assumed value of $\chi$ is 100. $\mathrm{d}=$ Tip to collector distance; $\mathrm{F}_{\mathrm{d}}=$ fiber diameter.

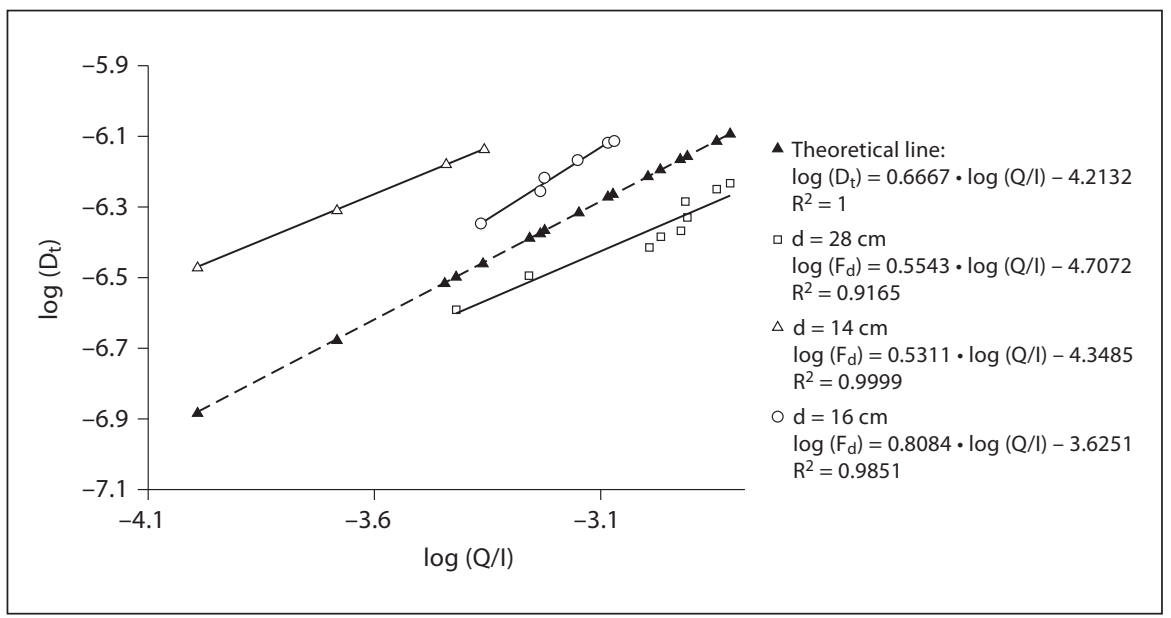

Yamaoka et al., 2006]. These observations are further corroborated by cells sensing FDL scaffold surfaces as 2D, similar to TCPs, thus losing their capacity to express C-II and overexpressing integrins [Schmal et al., 2006]. From our experimental analyses, submicron size topography was of fundamental importance in maintaining gene expression of C-II.

C-II and aggrecan are markers of chondrocyte redifferentiation, while C-I is an indicator of dedifferentiation [Schmal et al., 2006]. Dedifferentiation phenomena are not only related to diminished C-II and aggrecan production, but also to an increase in integrin expression [Loeser, 2000]. The expression of integrins was observed to be upregulated on FDL scaffolds, compared to the control and the fibrous mats. This observation is due to the chondrocytes adhering more to the FDL scaffolds (fig. 7, 8). While the absolute expressions of C-II and C-I are reliable indicators, the ratio of C-II/C-I is a better marker for characterizing the chondrocyte phenotype [Park et al., 2007]. The C-II/C-I ratio for cells cultured on NF scaffolds with a mean fiber diameter of $300 \mathrm{~nm}$ was 2 -fold higher than that for the control, suggesting that the cells preserve a more differentiated phenotype on these mats.

Recently, micropatterned substrates that contained ECM-coated adhesive islands of decreasing size [Chen et al., 1997] were shown to reorient the stress fibers and focal adhesions so that the forces were concentrated at the corner regions [Parker et al., 2002]. It has also been reported that the strength of the stress fiber is inversely proportional to the number of non-adherent cell borders [Théry et al., 2006]. In light of these published observations, we observe that on NFM, cells attach to more edges of the NF scaffolds with smaller fiber diameters, thus leaving more non-adherent cell borders, which is postulated to generate internal stress in the cell [Théry et al., 2006]. Focal adhesions are considered sensors and sites of origin of cytoskeletal forces [Geiger et al., 2001]. The effect of the nanofiber diameter on cell response can be appreciated by the very distinct features shown by cell morphology (actin fibers) on different diameter fiber mats (fig. 5).

Interestingly, cells seem to be tuned mechanically so that they preferentially differentiate on ECMs that have mechanical stiffness similar to that of their natural tissues [Engler et al., 2004; Georges and Janmey, 2005]. The shape and stiffness of the cells are governed by the interaction between microfilaments, microtubules and focal adhesions [Wang et al., 1993; Putnam et al., 2001; Ingber, 2003; Hu et al., 2004]. Compressive forces into the cells shift back and forth between microtubules and focal adhesions, such that ECM bears most of the load in spreadout cells on highly adhesive substrates, whereas microtubules bear most of the pre-stress in rounded cells with few anchoring points [Putnam et al., 2001; Hu et al., 2004]. Additionally, adapter proteins, including paxillin, talin and $\alpha$-actinin, form a complex, linking the $\beta_{1}$-integrin subunit and actin cytoskeleton and leading to the formation of actin stress fibers. This is perhaps the scenario in the case of cells cultured on FDL scaffolds and NFM with a mean fiber diameter of $1 \mu \mathrm{m}$, as shown in figure 5 , in which actin stress fibers and an upregulation in the gene expression of $\beta_{1}$-integrin subunit were noted. As noted earlier, ROCK-1 and mDial seem to act jointly in controlling cytoskeletal rearrangements [Mammoto et al., 2004]. Previous work has delineated the mechanistic pathways involved in probing of the external substrate by the cell 
and can be divided as follows: (1) the ROCK-1-dependent creation of force by the contractile apparatus, and (2) the response at the level of a single focal contact. The second step does not depend on ROCK-1 but does require mDia1. Furthermore, these signaling pathways depend on the level of GTP-Rho in the cell. Low levels are sufficient to activate the mDial pathway, while higher levels are necessary to activate the ROCK-1 pathway [Tsuji et al., 2002]. From our observations, the ROCK-1 pathway seems to be predominant in cells extracted from FDL and $1-\mu \mathrm{m}$ fiber diameter scaffolds, while the mDial pathway seems to be predominant in cells coming from 300-nm fiber diameter scaffolds.

SOX factors (L-Sox-5, Sox- 6 and Sox-9) are thought to be master regulatory genes that are essential for the expression of the chondrocyte phenotype [Lefebvre and De Crombrugghe, 1998; Bi et al., 1999; Bonassar et al., 2001]. A decrease in the level of transcriptional coactivators, LSox-5 and Sox-6, in chondrocyte micromass cultures led to a decrease in C-II expression [Woods and Beier, 2006]. In our experiments, an upregulation of Sox-9 was not detected for cells cultured on NFM with a mean diameter of $300 \mathrm{~nm}$, but Sox-5 was modestly upregulated with the C-II/C-I ratio. All together, these results suggest that an upregulation in the expression of chondrocytic markers, namely C-II and aggrecan, on NFM with a mean fiber diameter of $300 \mathrm{~nm}$ is more likely associated with an upregulation in mDia 1 and Sox-5 when compared to ROCK1 and Sox-9.
In conclusion, the molecular mechanisms responsible for the regulation of gene expression on scaffolds and artificial matrices are largely unknown, but our studies strongly suggest that there is an interrelationship between mat fiber diameter and gene expression activation. Our results suggest that matrix geometry can be used to keep genotype differentiation of chondrocytes in culture. This study provides additional insights into the chondrocyte behavior on fibrous surfaces. It is already known that a reduced number of actin fibers promotes chondrogenesis [Benjamin et al., 1994; Trickey et al., 2004]. We suggest that a mechanosensitive cascade is activated in response to the fiber diameters. This cascade is possibly a RhoA/ROCK-1/mDial signaling pathway, where transcription factors Sox-9 and L-Sox-5 seem to be involved due to the activation or deactivation of C-II production. While the differences in the gene expression of certain factors evaluated were modest, studies are in progress to evaluate the regulation of gene expression, both in the presence and absence of external mechanical cues and growth factors.

\section{Acknowledgements}

This work was supported by the National Institutes of Health (R21EB006046).

\section{References}

Badami, A.S., M.R. Kreke, et al. (2006) Effect of fiber diameter on spreading, proliferation, and differentiation of osteoblastic cells on electrospun poly(lactic acid) substrates. Biomaterials 27: 596-606.

Bashur, C.A., R.D. Shaffer, et al. (2009) Effect of fiber diameter and alignment of electrospun polyurethane meshes on mesenchymal progenitor cells. Tissue Eng Part A 15: 1-11.

Benjamin, M., C.W. Archer, et al. (1994) Cytoskeleton of cartilage cells. Microsc Res Tech 28: 372-377.

Benya, P.D., J.D. Shaffer (1982) Dedifferentiated chondrocytes reexpress the differentiated collagen phenotype when cultured in agarose gels. Cell 13: 215-224.

Bhattarai, S.R., N. Bhattarai, et al. (2006) Hydrophilic nanofibrous structure of polylactide, fabrication and cell affinity. J Biomed Mater Res A 78: 247-257.
Bhattarai, N., D. Edmonson, et al. (2005) Electrospun chitosan-based nanofibers and their cellular compatibility. Biomaterials 26: 6176-6184.

Bi, W., J.M. Deng, et al. (1999) Sox9 is required for cartilage formation. Nat Genet 22: 85.

Bonassar, L.J., A.J. Grodzinsky, et al. (2001) The effect of dynamic compression on the response of articular cartilage to insulin-like growth factor I. J Orthop Res 19: 11-17.

Britland, S., H. Morgan, et al. (1996) Synergistic and hierarchical adhesive and topographic guidance of BHK cells. Exp Cell Res 228: 313-325.

Bryant, S.J., K.S. Anseth (2002) Hydrogel properties influence ECM production by chondrocytes photoencapsulated in poly(ethylene glycol) hydrogels. J Biomed Mater Res 59: 63-72.

Chen, C.S., M. Mrksich, et al. (1997) Geometric control of cell life and death. Science 276: 1425-1428.
Clark, P., P. Connoly, et al. (1987) Topographical control of cell behaviour. 2. Multipl grooved substrata. Development 108: 635-644.

Cukierman, E., R. Pankov, et al. (2001) Taking cell-matrix adhesions to the third dimension. Science 294: 1708-1712.

Dahlberg, L., A. Kreicbergs (1991) Demineralized allogeneic bone matrix for cartilage repair. J Orthop Res 9: 11-19.

Dalby, M.J., M.O. Riehle, et al. (2004) Fibroblast response to a controlled nanoenvironment produced by colloidal lithography. J Biomed Mater Res A 69: 314-322.

Dalby, M.J., M.O. Riehle, et al. (2005) Morphological and microarray analysis of human fibroblasts cultured on nanocolumns produced by colloidal lithography. Eur Cell Mater 9: $1-8$

Darling, E.M., K.A. Athanasiou (2003a) Articular cartilage bioreactors and bioprocesses. Tissue Eng 9: 9-26. 
Darling, E.M., K.A. Athanasiou (2003b) Biomechanical strategies for articular cartilage regeneration. Ann Biomed Eng 31: 1114-1124.

Davis, A., K.S. Anseth (2002) Controlled release from crosslinked degradable networks. Crit Rev Ther Drug Carrier Syst 19: 385-423

Duan, B., C. Dong, et al. (2004) Electrospinning of chitosan solutions in acetic acid with poly(ethylene oxide). J Biomater Sci Polym Ed 15: 797-811.

Durrant, L.A., C.W. Archer, et al. (1999) Organisation of the chondrocyte cytoskeleton and its response to changing mechanical conditions in organ culture. J Anat 194: 343-353.

Engler, A.J., M.A. Griffin, et al. (2004) Myotubes differentiate optimally on substrates with tissue-like stiffnes: pathological implications of soft or stiff microenvironment. J Cell Biol 166: 877-887.

Enomoto-Iwamoto, M., M. Iwamoto, et al. (1997) Involvement of $\alpha_{5} \beta_{1}$ integrin in matrix interactions and proliferation of chondrocytes. J Bone Miner Res 12: 1124-1132.

Frenkel, S.R., B. Toolan, et al. (1997) Chondrocyte transplantation using a collagen bilayer matrix for cartilage repair. J Bone Joint Surg 79: 831-836.

Fridrikh, S.V., J.H. Yu, et al. (2003) Controlling the fiber diameter during electrospinning. Phys Rev Lett 90: 1445021-1445024.

Frondoza, C., A. Sohrabi, et al. (1996) Human chondrocytes proliferate and produce matrix components in microcarrier suspension culture. Biomaterials 17: 879-888.

Geiger, B., A. Bershadsky, et al. (2001) Transmembrane extracellular matrix-cytoskelton crosstalk. Nat Rev Mol Cell Biol 2: 793-805.

Georges, P.C., P.A. Janmey (2005) Cell type specific response to growth on soft material. J Appl Physiol 98: 1547-1553.

Grande, D.A., C. Halberstadt, et al. (1997) Evaluation of matrix scaffolds for tissue engineering of articular cartilage grafts. J Biomed Mater Res 34: 211-220.

Hsu, S.H., C.L. Tsai, et al. (2002) Evaluation of cellular affinity and compatibility to biodegradable polyesters and type-II collagenmodified scaffolds using immortalized rat chondrocytes. Artif Organs 26: 647-658.

-Hu, S., J. Chen, et al. (2004) Cell spreading controls balance of prestress by microtubules and extracellular matrix. Front Biosci 9: 2177-2182.

-Idowu, B., M.M. Knight, et al. (2000) Confocal analysis of cytoskeletal organisation within isolated chondrocyte sub-populations cultured in agarose. Histochem J 32: 165-174.

- Ingber, D.E. (2003) Tensegrity. 1. Cell structure and hierarchical systems biology. J Cell Sci 116: 1157-1173.

- Ishizaki, T., Y. Morishima, et al. (2001) Coordination of microtubules and the actin cytoskeleton by the Rho effector mDia1. Nat Cell Biol 3: 8-14.
Kidoaki, S., I.K. Kwon, et al. (2005) Mesoscopic spatial designs of nano- and microfiber meshes for tissue-engineering matrix and scaffold based on newly devised multilayering and mixing electrospinning techniques. Biomaterials 26: 37-46.

Kino-Oka, M., Y. Maeda, et al. (2005) Process design of chondrocyte culture with monolayer growth for cell expansion and subsequent three-dimensional growth for production of cultured cartilage. J Biosci Bioeng 100: 67-76.

Langer, R., J. P. Vacanti (1993) Tissue engineering. Science 260: 920-926.

Lee, I.S., I.K. Kwon, et al. (2004) Nanofabrication of microbial polyester by electrospinning promotes cell attachment. Macromol Res 12: 374-378.

Lee, H.S., S.J. Millward-Sadler, et al. (2000) Integrin and mechanosensitive ion channel-dependent tyrosine phosphorylation of focal adhesion proteins and beta-catenin in human articular chondrocytes after mechanical stimulation. J Bone Miner Res 15: 15011509 .

Lefebvre, V., B. De Crombrugghe (1998) Toward understanding SOX9 function in chondrocyte differentiation. Matrix Biol 16: 529.

Li, W.J., K.G. Danielson, et al. (2003) Biological response of chondrocyte culture in three-dimensional nanofibrous poly(epsilon-caprolactone) scaffolds. J Biomed Mater Res A 67: 1105-1114.

Li, W.J., C.T. Laurencin, et al. (2002) Electrospun nanofibrous structure: a novel scaffold for tissue engineering. J Biomed Mater Res 60: 613-621.

Loeser, R.F. (2000) Chondrocyte integrin expression and function. Biorheology 37: 109116.

Lucchinetti, E., M. Bhargava, et al. (2004) The effect of mechanical load on integrin subunits $\alpha_{5}$ and $\beta_{1}$ in chondrocytes from mature and immature cartilage explants. Cell Tissue Res 315: 385-391.

Ma, Z., C. Gao, et al. (2002) Immobilization of natural macromolecules on poly-L-lactic acid membrane surface in order to improve its cytocompatibility. J Biomed Mater Res 63 : 838-847.

Mammoto, A., S. Huang, et al. (2004) Role of RhoA, mDia and ROCK in cell shape-dependent control of the Skp2-p27kip1 pathway and the G1/S transition. J Biol Chem 279: 26323-26330.

Maroudas, A. (1979) Adult Articular Cartilage, ed 2. Tunbridge, Pitman Medical.

Matthews, J.A., E.D. Boland, et al. (2003) Electrospinning of collagen type II. A feasibility study. J Bioact Compat Polym 18: 125-134.

Matthews, J.A., G.E. Wnek, et al. (2002) Electrospinning of collagen nanofibers. Biomacromolecules 3: 232-238.

McFarland, C.D., C.H. Thomas, et al. (2000) Protein adsorption and cell attachment to patterned surfaces. J Biomed Mater Res 49: 200-210.
-Millward-Sadler, S.J., D.M. Salter (2004) Integrin-dependent signal cascade in chondrocyte mechanotransduction. Ann Biomed Eng 32: 435-446.

Minns, R.J., D.S. Muckle, et al. (1983) The repair of osteochondral defects in osteoarthritic rabbit knees by the use of carbon fibre. Biomaterials 3: 81-86.

Nerem, R.M. (2000) The challenge of imitating nature; in Lanza, R.P., R. Langer, J.P. Vacanti (eds): Principles of Tissue Engineering. San Diego, Academic Press.

Noriega, S., T. Mamedov, et al. (2007) Intermittent applications of continuous ultrasound on the viability, proliferation, morphology, and matrix production of chondrocytes in 3D matrices. Tissue Eng 13: 611-618.

Park, K., B.-H. Min, et al. (2007) Quantitative analysis of temporal and spatial variations of chondrocyte behavior in engineered cartilage during long-term culture. Ann Biomed Eng 35: 419-428.

Parker, K.K., A.L. Brock, et al. (2002) Directional control of lamellipodia extension by constraining cell shape and orienting cell tractional forces. FASEB J 16: 1195-1204.

Powell, H.M., D.A. Kniss, et al. (2006) Nanotopographic control of cytoskeletal organization. Langmuir 22: 5087-5094.

Priddy, N.H., 2nd, J.L. Cook, et al. (2001) Effect of ascorbate and two different media on canine chondrocytes in three-dimensional culture. Vet Ther 2: 70-77.

Putnam, A.J., K. Schultz, et al. (2001) Control of microtubule assembly by extracellular matrix and externally applied strain. Am J Physiol 280: C556-C564.

Rocha, L.B., G. Goissis, et al. (2002) Biocompatibility of anionic collagen matrix as scaffold for bone healing. Biomaterials 23: 449-456.

Schmal, H., A. Mehlhorn, et al. (2006) Regulative mechanism of chondrocyte adhesion. Tissue Eng 12: 741-750.

$\checkmark$ Schuman, L., P. Buma, et al. (1995) Chondrocyte behaviour within different types of collagen gel in vitro. Biomaterials 16: 809-814.

Spiteri, C.C., R.M. Pilliar, et al. (2006) Substrate porosity enhances chondrocyte attachment, spreading, and cartilage tissue formation. J Biomed Mater Res A 78: 676-683.

Subramanian, A., H.-Y. Lin, et al. (2004) Synthesis and evaluation of scaffolds prepared from chitosan fibers for potential use in cartilage tissue engineering. Biomed Sci Instrum 40: 117-122.

Subramanian, A., D. Vu, et al. (2005) Preparation and evaluation of the electrospun chitosan/PEO fibers for potential applications in cartilage tissue engineering. J Biomater Sci Polym Ed 16: 861-873.

Terada, S., H. Yoshimoto, et al. (2005) Hydrogel optimization for cultured elastic chondrocytes seeded onto a polyglycolic acid scaffold. J Biomed Mater Res A 75: 907-916. 
Théry, M., A. Pépin, et al. (2006) Cell distribution of stress fibers in response to the geometry of the adhesive environment. Cell Motil Cytoskeleton 63: 341-355.

-Thomas, C.H., J.B. Lhoest, et al. (1999) Surfaces designed to control the projected area and shape of individual cells. J Biomech Eng 121: 40-48.

Torres, A.J., B. Wu, et al. (2008) Nanobiotechnology and cell biology: micro- and nanofabricated surfaces to investigate receptor-mediated signaling. Annu Rev Biophys 37: 265288.

Trickey, W.R., T.P. Vail, et al. (2004) The role of the cytoskeleton in the viscoelastic properties of human articular chondrocytes. J Orthop Res 22: 131-139.

- Tsuji, T., T. Ishizaki, et al. (2002) ROCK and mDial antagonize in Rho-dependent Rac activation in Swiss 3T3 fibroblasts. J Cell Biol 157: 819-830. van Susante, J.L., P. Buma, et al. (1995) Culture of chondrocytes in alginate and collagen carrier gels. Acta Orthop Scand 66: 549-556.

von der Mark, K., V. Gauss, et al. (1977) Relationship between cell shape and type of collagen synthesized as chondrocytes lose their cartilage phenotype in culture. Nature 267: 531532.

Wakitani, S., G. Tatsuhiko, et al. (1994) Mesenchymal cell-based repair of large, full-thickness defects of articular cartilage. J Bone Joint Surg 76: 579-592.

-Wang, N., J.P. Butler, et al. (1993) Mechanotransduction across the cell surface and through the cytoskeleton. Science 260: 1124-1127.

Wnek, G.E., M.E. Carr, et al. (2003) Electrospinning of nanofiber fibrinogen structures. Nanoletters 3: 213.

Wong, M., D.R. Carter (2003) Articular cartilage functional histomorphology and mechanobiology: a research perspective. Bone 33: $1-13$.
Wood, M.A., P. Bagnaninchi, et al. (2008) The beta integrins and cytoskeletal nanoimprinting. Exp Cell Res 314: 927-935.

Woods, A., F. Beier (2006) RhoA/ROCK signaling regulates chondrogenesis in a contextdependent manner. J Biol Chem 281: 1313413140

Yamaoka, H., H. Asato, et al. (2006) Cartilage tissue engineering using human articular chondrocytes embedded in different hydrogel materials. J Biomed Mater Res A 78: 1-11.

Yang, F., C.Y. Xu, et al. (2004) Characterization of neural stem cells on electrospun poly(Llactic acid) nanofibrous scaffold. J Biomater Sci Polym Ed 15: 1483-1497.

Yoshimoto, H., Y.M. Shin, et al. (2003) A biodegradable nanofiber scaffold by electrospinning and its potential for bone tissue engineering. Biomaterials 24: 2077-2082. 